\title{
RETURN DISTRIBUTIONS OF STRATEGIC GROWTH OPTIONS
}

\author{
Hans Haanappel
}

\author{
ERIM \\ Erasmus University, Rotterdam, The Netherlands \\ hthaanappel@few.eur.nl \\ Fax 011-31-10-4526399
}




\title{
RETURN DISTRIBUTIONS OF STRATEGIC GROWTH OPTIONS
}

\begin{abstract}
In this study we develop implications for the return distribution of firms with embedded strategic growth options. In our model we integrate real option theory with a Cournot-Nash framework where two firms choose output levels endogenously and may have investment-timing differences. Simulations of the returns of the strategic growth option show that traditional option variables, such as the value of the project relative to the investment (i.e., moneyness of the growth option), the return interval relative to the period the project can be deferred (i.e., maturity), and uncertainty in demand for the product are significant determinants for the moments of the distribution of the option returns. In addition to these option variables, uncertain preemption may introduce discontinuities in the payoff of our model and consequently further enhance skewness and kurtosis. Investment-timing differences between competitors may even lead to bimodal return distributions, where the firm with a first-mover advantage has a high probability to generate high returns.
\end{abstract}




\section{INTRODUCTION}

This paper aims to understand the return distribution of strategic growth options under imperfect competition. Growth stocks exhibit a typical behavior that is distinguishably different from value stocks. High volatility, discontinuities and value asymmetries characterize growth stocks, while these characteristics are to a lesser extent observed for value stocks. We propose that some of the return dynamics of growth stocks can be attributed to real options characteristics and the competitive environment the firm faces. The implicit leverage and nonlinear payoff profile of embedded growth options amplify uncertainty and introduce skewness and kurtosis in the return distribution. Furthermore, the ability of the firm to capitalize on its growth opportunities is subject to competition and competitive interaction may introduce discontinuities in the value of the firm. Investment-timing differences may even cause bimodal distributions of strategic growth option returns.

The early real options literature shows that the option value of waiting leads firms to invest only at a substantial premium over the net present value of immediate investment. ${ }^{1}$ Often the models are based on the critical assumption that the investment opportunity presents itself in either a monopoly or a perfectly competitive market. However, competition for shared growth opportunities can dramatically erode the value of waiting and often leads to investment near the zero net present value threshold. New literature integrates the real options approach with game theory and makes a more complete assessment of strategic growth options under imperfect competition.

In the early real option game literature, Smit and Trigeorgis (1997) analyze a twostaged game where growth option value depends on endogenous competitive reactions. Kulatilaka and Perotti (1998) show that when firms can acquire a strategic advantage by investing in a growth option, higher uncertainty encourages immediate investment as profits are a convex function of uncertain demand. Perotti and Kulatilaka (1999) examine the valuation of a Stackelberg growth option in a Cournot-Nash framework where a firm has a time-to-market advantage. The authors show that the value of such strategic investment is unambiguously increasing in demand uncertainty, thereby justifying the early exercise of the strategic option. Grenadier (1996) develops an equilibrium 
framework for option exercise games and applies it to real estate market. The model provides a rational equilibrium foundation for the development cascades and overbuilding in real estate markets. Grenadier (1999) analyzes the case of strategic equilibrium exercise strategies under asymmetric information over the underlying option parameters. Grenadier (2000) provides a general and tractable solution approach for deriving the equilibrium investment strategies of firms in a Cournot-Nash framework in a continuous-time stochastic setting. ${ }^{2}$ Lambrecht and Perraudin (2003) provide an exercise game in which firms take preemption effects and incomplete information into account.

Another strand of literature that is related to this paper is focused on option and real option returns (e.g. Rubinstein (1984), Berk, Green and Naik (1998) and Shackleton and Wojakowski (2000)). Cox, Ross and Rubinstein (1979) and Galai and Masulis (1976) show that the expected rate of return of a European option is related to the expected rate of return of the underlying asset and the option elasticity. Coval and Shumway (2001) empirically analyze the expected return of options traded in financial markets. In the real options literature, Berk, Green and Naik (2003) simulate the return distributions of a multi-stage investment project and capture many option features of R\&D-ventures and start-up companies that affect return distributions. Their research shows that the required rate of return of an investment is high in its early life and will decrease as it approaches a state of completion. This is a result of the changing implicit leverage of a compound option and the resolution of technical uncertainty over time. Furthermore they show that the option to abandon combined with technological uncertainty produces bimodal return distributions as one may expect in high-risk, technological ventures.

\footnotetext{
1 The books by Dixit and Pindyck (1994) and Trigeorgis (1996) provide a nice treatment of real option investment and valuation under uncertainty. The books of Grenadier (2000) and Smit and Trigeorgis (2004) provide an overview of the literature and applications of real option games.

2 Grenadier (2000) shows that the Nash equilibrium exercise strategies are identical to those obtained in an "artificial" perfectly competitive equilibrium with a slightly modified demand function.
} 
By introducing imperfect competition with uncertain preemption effects and investment-timing differences, we aim to take another step in understanding the risk and return characteristics of strategic options. We simulate the return distribution of the strategic growth option in a Cournot-Nash setting, where two firms share the growth opportunity in the industry. We find that continuous-time option returns are negatively skewed and have fat tails due to the asymmetrical payoff structure inherent to the option's nature. The return interval relative to the maturity of the growth option, the moneyness of the growth option and uncertainty in demand are significant determinants of its return distribution. Strategic interaction and preemption effects may cause discontinuities in the payoff function of growth options and introduce more skewness and kurtosis in the return distribution. When investment-timing differences are important, bimodal distributions of growth option returns may even result.

This paper is organized as follows. In section I we develop a model for valuing a growth option under imperfect competition in a sequential investment game where the existence of a first-mover advantage may result in investment-timing differences. In section II we simulate the return distribution of the strategic growth option and derive implications for the return distribution based on the different option and strategic parameters. Section III offers some concluding remarks. 


\section{VALUATION OF A SEQUENTIAL GROWTH OPTION GAME}

In this section we develop a valuation model for a shared growth option. The market structure of this sequential investment game is endogenous as a consequence of investment-timing differences and preemption of the market opportunity.

\section{A. Sequential Investment Game with Endogenous Quantity and Market Structure}

Suppose two firms ( $\mathrm{i}=\mathrm{A}$ or B) share a growth opportunity to make an investment, $\mathrm{I}_{\mathrm{i}}$, at $\mathrm{t}_{1}$ or $\mathrm{t}_{2}$ to capture a profit flow. If a firm doesn't exercise the growth option at the end node, the investment opportunity expires worthless. Figure 1 shows the sequential investment game in extensive form. The alternative actions by each firm i to make the investment (I) or to defer (D) are shown by squares $(\square)$ along the tree branches. At $t_{1}$ we can identify four investment-timing scenarios: (i) both firms invest resulting in a symmetrical Cournot payoff; (ii) when both firms defer they face an option on a symmetrical Cournot payoff in the next period; (iii) and (iv) when one firm invests and the other defers investment, the first mover becomes the leader (L), and thereby acquires a Stackelberg leader payoff. The follower (F) has an option on a Stackelberg follower payoff in the next period. The circles (o) show the resolution of the uncertain demand parameter $(\theta)$ over time.

We note that the payoff of the growth option involves different competitive interactions. This interaction exists due to endogenous quantities and investment-timing differences. In the extreme, the market structure may change altogether as a consequence of preemption of the opportunity. The optimal investment and production strategy of a firm In our model therefore not only depends on the level of demand but also on the production and investment decisions made by its competitor. Applying the process of backward induction and option valuation techniques we determine the equilibrium payoff as a function of the level of demand. The value of the shared growth option for each firm is then calculated by taking the risk-neutral expectation of the equilibrium payoff.

$<$ Insert Figure 1 about here $>$ 


\section{B. Payoff Functions for Different Market Structures}

We assume that market demand for a product is linear in prices and an increasing function of the stochastic demand parameter $\theta$. Let $\mathrm{P}(\mathrm{Q})$ be the inverse demand function, expressing the market price as a function of total output $\mathrm{Q}: \mathrm{P}(\mathrm{Q}, \theta)=\theta-\mathrm{Q}$, where $\theta$ is distributed on $(0, \infty)$ with an expected value $\mathrm{E}(\theta) \equiv \theta>0$. In our model, $\theta$ follows a Geometric Brownian Motion, that is:

$d \theta=\alpha \theta d t+\sigma \theta d z$

where, $d \theta$ is the change in $\theta$ for an infinitive small time period dt, $\alpha$ is the risk neutral drift rate of $\theta, \sigma$ is the instantaneous standard deviation and $\mathrm{dz}$ is an increment of a Wiener process. ${ }^{3}$ Suppose a firm has to decide to invest an amount I in order to capture the profit flow. Without an option to defer, a firm will invest if the present value of the profit flow exceeds investment outlay. For simplicity we assume the absence of cost and asymmetries in investment outlays. The optimal profit of firm $i, \pi_{i}$, then equals:

$\pi_{i}=\frac{\theta^{2}}{n}$

where $\theta$ is the stochastic demand parameter and $\mathrm{n}$ reflects a parameter for the market structure. In case of a monopoly $\mathrm{n}=4$, for a Stackelberg leader $\mathrm{n}=8$, for symmetrical Cournot competitor $\mathrm{n}=9$, and for a Stackelberg follower $\mathrm{n}=16$.

\footnotetext{
3 The risk neutral drift rate, $\alpha$ can be determined by subtracting the risk premium, $\gamma$, from the risk averse drift rate in $\theta, \mu$. The risk premium can be determined as follows: $\gamma=\rho_{\theta, \mathrm{m}} \sigma / \sigma_{\mathrm{m}} \varphi$. Where $\rho_{\theta, \mathrm{m}}$ is the correlation between the return on the market portfolio and the return on $\theta, \sigma$ is the standard deviation of the return of $\theta, \sigma_{\mathrm{m}}$ is the standard deviation of the return of the market portfolio and $\varphi$ is the market risk premium.
} 
The present value of the profit flow, V, can be found by discounting the risk neutral profits with the risk free rate, according to:

$$
V=\int_{t=0}^{\infty} \pi_{i}\left(\theta_{t}\right) e^{-r_{f} t} d t=\int_{t=0}^{\infty} \frac{\theta_{t}^{2}}{n} e^{-r_{f} t} d t
$$

where, $r_{\mathrm{f}}$ is the risk free rate. Solving this integral yields the following equation for the present value of the profit flow: 4

$$
V=\frac{\theta^{2}}{n\left(r_{f}-2 \alpha-\sigma^{2}\right)}
$$

Note that $2 \alpha+\sigma^{2}<\mathrm{r}_{\mathrm{f}}$ in order for the value to converge. A firm will invest only if the present value of the profit flow exceeds the investment outlay, that is if $\mathrm{V}>\mathrm{I}$. Based on this investment rule we can derive a general investment threshold function, $\theta^{*}$, for each market structure:

$$
\theta^{*}=\sqrt{n\left(r_{f}-2 \alpha-\sigma^{2}\right) I}
$$

In Equation 5 the investment threshold is an increasing function of the risk free rate, $\mathrm{r}_{\mathrm{f}}$, and the investment outlay, I, while it is negatively related to the risk neutral drift, $\alpha$, the market structure, $\mathrm{n}$, and uncertainty in demand, $\sigma .5$ Table 1 presents an overview of the profit function, the value function and the investment thresholds for different market structures.

$<$ Insert Table 1 about here $>$

\footnotetext{
${ }^{4}$ For the proof we refer to Appendix 1, see also Dixit and Pindyck (1994) pp. 82, Equations 33-34.

5 Because profits are convex in demand, a negative relationship between the investment threshold and uncertainty in demand exists (Jensens Inequality). In other words, under imperfect competition profits are convex in demand, since firms respond to better market conditions by increasing both output and prices. Thus expected profits increase with volatility as high marginal revenues at higher levels of demand more than compensate for low revenues at low levels of demand.
} 
Ad i) Both firms invest, $N P V_{C}\left(\theta_{t 1}\right)$

When both firms invest at $t_{1}$, the outcome is a symmetrical Cournot Nash-equilibrium where each firm reacts optimally to the other firm's quantity. The net present value, $\operatorname{NPV}_{C}\left(\theta_{t 1}\right)$, for each firm then equals

$$
N P V_{C}\left(\theta_{t_{1}}\right)=\frac{\theta_{t_{1}}^{2}}{9\left(r_{f}-2 \alpha-\sigma^{2}\right)}-I
$$

Ad ii) Both firms defer investment, $F_{C}\left(\theta_{t 1}\right)$

When both firms defer investment at $t_{1}$ they face an option on a symmetrical Cournot payoff in the next period, $t_{2}$. The value of the option to defer, $F_{C}\left(\theta_{t 1}\right)$, assuming that the market structure will be symmetrical Cournot competition at $t_{2}$, can be obtained by the following equation: 6

$$
F_{C}\left(\theta_{t_{1}}\right)=\frac{\theta_{t_{1}}^{2} e^{\left(\sigma^{2}+2 \alpha-r_{f}\right)\left(t_{2}-t_{1}\right)}}{9\left(r_{f}-2 \alpha-\sigma^{2}\right)} N\left[d_{1}\right]-I e^{-r_{f}\left(t_{2}-t_{1}\right)} N\left[d_{2}\right]
$$

with

$$
d_{1}=\frac{\ln \left(\frac{\theta_{t_{1}}}{\theta_{C}}\right)+\left(\alpha+\frac{3}{2} \sigma^{2}\right)\left(t_{2}-t_{1}\right)}{\sigma \sqrt{t_{2}-t_{1}}} \text { and } d_{2}=d_{1}-2 \sigma \sqrt{t_{2}-t_{1}}
$$

Ad iii and iv) Leader/follower payoff, $N P V_{L}\left(\theta_{t 1}\right), F_{F}\left(\theta_{t 1}\right)$

When a firm defers at $t_{1}$, it acquires an option to invest at $t_{2}$ and becomes a follower, $F$. The value of the growth option for the follower at $t_{1}, F_{F}\left(\theta_{t 1}\right)$, can be determined along the lines of the valuation of Cournot competition using Equation (7): ${ }^{7}$

\footnotetext{
6 For proof see Appendix 2.

7 A similar formula can be applied for valuing the growth option assuming that both firms defer investment. However, the investment threshold will be that of a Stackelberg follower, $\theta_{\mathrm{F}}$, as the quantity set by a follower will be lower than that of symmetrical Cournot competitor and we have to replace $\mathrm{n}=9$ with $\mathrm{n}=16$.
} 
$F_{F}\left(\theta_{t_{1}}\right)=\frac{\theta_{t_{1}}^{2} e^{\left(\sigma^{2}+2 \alpha-r_{f}\right)\left(t_{2}-t_{1}\right)}}{16\left(r_{f}-2 \alpha-\sigma^{2}\right)} N\left[d_{3}\right]-I e^{-r_{f}\left(t_{2}-t_{1}\right)} N\left[d_{4}\right]$

with

$d_{3}=\frac{\ln \left(\frac{\theta_{t_{1}}}{\theta_{F}}\right)+\left(\alpha+\frac{3}{2} \sigma^{2}\right)\left(t_{2}-t_{1}\right)}{\sigma \sqrt{t_{2}-t_{1}}}$ and $d_{4}=d_{3}-2 \sigma \sqrt{t_{2}-t_{1}}$

The valuation function for the leader, L, is more complicated as a consequence of uncertain preemption. If firm $L$ invests at $t_{1}$, it will generate a monopoly profit flow of $\pi_{M}(\theta)$ over $\left[t_{1}, t_{2}\right]$. The market structure that the leader will face at $t_{2}$ will depend on the investment decision made by the follower. The leader will generate an infinitive monopoly profit if the follower does not invest at $t_{2}$, that is if $\theta_{\mathrm{t} 2}<\theta_{\mathrm{F}}$. However, if the follower does invest at $\mathrm{t}_{2}$, implying $\theta_{\mathrm{t} 2}>\theta_{\mathrm{F}}$, the leader will generate a Stackelberg leader profit flow from $t_{2}$ onwards. The net present value of the profit flow of the leader, $\operatorname{NPV}_{\mathrm{L}}\left(\theta_{\mathrm{t} 1}\right)$, can therefore be written as the net present value of an infinitive monopoly profit flow minus an written option reflecting the possibility that the follower exercises its growth option at $\mathrm{t}_{2}$, changing the market structure from a Monopoly to that of a Stackelberg leader/follower game. The payoff of the leader can therefore be calculated as follows:

$N P V_{L}\left(\theta_{t_{1}}\right)=\frac{\theta_{t_{1}}^{2}}{4\left(r_{f}-2 \alpha-\sigma^{2}\right)}-\frac{\theta_{t_{1}}^{2} e^{\left(\sigma^{2}+2 \alpha-r_{f}\right)\left(t_{2}-t_{1}\right)}}{8\left(r_{f}-2 \alpha-\sigma^{2}\right)} N\left[d_{4}\right]-I$

\section{Solution of the Sequential Investment Game}

The equilibrium payoff and optimal investment strategy at $t_{1}$ is a function of the level of demand. We expect that for high levels of demand both firms invest, while for low levels of demand both firms defer investment. For intermediate levels of demand, market demand is not sufficient to accommodate both firms. In this demand region an equilibrium results where only one firm invests (leader), while the other firm (follower) defers the investment decision to the next period. The investment thresholds that trigger 
certain investment policies (both invest, both defer and leader invests and follower defers) and determine the market structure, can be found by elimination of strictly dominated strategies.

For a given level of demand, both firms will invest if the following conditions are met on $\mathrm{t}_{1}: \operatorname{NPV}_{\mathrm{C}}\left(\theta_{\mathrm{t} 1}\right)>\mathrm{F}_{\mathrm{F}}\left(\theta_{\mathrm{t} 1}\right)$ and $\operatorname{NPV}_{\mathrm{L}}\left(\theta_{\mathrm{t} 1}\right)>\mathrm{F}_{\mathrm{C}}\left(\theta_{\mathrm{t} 1}\right)$. This situation will occur if $\theta_{\mathrm{t} 1}>\theta_{\mathrm{II}}$, where $\theta_{\mathrm{II}}$ is the investment threshold that satisfies both conditions. Therefore $\theta_{\text {II }}=\max \left[\theta_{1} ; \theta_{2}\right]$, where $\theta_{1}$ and $\theta_{2}$ can be numerically found by solving the value equations with $\operatorname{NPV}_{C}\left(\theta_{1}\right)=F_{F}\left(\theta_{1}\right)$ and $\operatorname{NPV}_{L}\left(\theta_{2}\right)=F_{C}\left(\theta_{2}\right)$. Both firms will defer investment if the following conditions are met on $\mathrm{t}_{1}$ : $\operatorname{NPV}_{\mathrm{L}}\left(\theta_{\mathrm{t} 1}\right)<\mathrm{F}_{\mathrm{C}}\left(\theta_{\mathrm{t} 1}\right)$ and $\operatorname{NPV}_{\mathrm{C}}\left(\theta_{\mathrm{t} 1}\right)<\mathrm{F}_{\mathrm{F}}\left(\theta_{\mathrm{t} 1}\right)$. This situation will occur if $\theta_{\mathrm{t} 1}<\theta_{\mathrm{WW}}$, where $\theta_{\mathrm{WW}}=\min \left[\theta_{1} ; \theta_{2}\right]$. Thus for $\theta_{\mathrm{t} 1}>\theta_{\mathrm{II}}$ and $\theta_{\mathrm{t} 1}<\theta_{\mathrm{wW}}$ firms will pursue pure investment strategies: either both invest or both defer.

However, there is a region of demand, $\theta_{\mathrm{t} 1} \in\left[\theta_{\mathrm{WW}}, \theta_{\mathrm{II}}\right]$, where multiple equilibria may exist and the notion of a simultanous or dynamic game is critical. Firms will pursue mixed investment strategies in the intermediate demand zone if they move simultanous and don't observe each others actions. In the dynamic version of the game, firms will invest sequentially and the second mover observes and reacts optimally to the firstmover's investment strategy. In the intermediate demand zone the first mover invests, because $\mathrm{F}_{\mathrm{F}}(\theta)<\mathrm{NPV}_{\mathrm{L}}(\theta)$ for $\theta_{\mathrm{t} 1} \in\left[\theta_{\mathrm{WW}}, \theta_{\mathrm{II}}\right]$, while the follower defers the investment decision to the next period. Figure 2 illustrates the demand zones and equilibrium payoff functions in our sequential investment game for different levels of demand.

$<$ Insert Figure 2 about here $>$

After we have determined the critical thresholds, $\theta_{\mathrm{WW}}$ and $\theta_{\mathrm{II}}$, we are able to value the growth option by solving the following integral using the risk neutral valuation approach: ${ }^{8}$

$$
F_{i}(\theta)=e^{-r_{f} t_{1}}\left[\int_{0}^{\theta_{W W}} F_{C} p\left(\theta_{t_{1}}\right) d \theta+\int_{\theta_{W W}}^{\theta_{I I}}\left[\zeta_{i} N P V_{L}+\left(1-\zeta_{i}\right) F_{F}\right] p\left(\theta_{t_{1}}\right) d \theta+\int_{\theta_{I I}}^{\infty} N P V_{C} p\left(\theta_{t_{1}}\right) d \theta\right]
$$

\footnotetext{
${ }^{8}$ Because the thresholds $\theta_{\mathrm{WW}}$ and $\theta_{\mathrm{II}}$ can only be found numerically, there exists no closed form solution for the value of the growth option.
} 
where $F_{i}(\theta)$ is the value of the shared growth option for firm $i$ and $\zeta_{i}$ is a parameter that indicates whether the firm is a first mover $\left(\zeta_{\mathrm{i}}=1\right)$ or a follower $\left(\zeta_{\mathrm{i}}=0\right)$.

\section{RETURN DISTRIBUTIONS OF STRATEGIC GROWTH OPTIONS}

Based on our sequential investment game discussed in the previous section we simulate the return distribution of the shared growth option over a return interval, $\Delta t$, where $\Delta \mathrm{t}=\mathrm{t}^{*}-\mathrm{t}_{0}$ and $\mathrm{t}^{*}<\mathrm{t}_{1}$. We simulate 100,000 trajectories of $\theta$, where $\theta$ is lognormal distributed according to Equation (1):

$\ln \left(\frac{\theta_{t^{*}}}{\theta_{0}}\right) \sim N\left(\left(\mu-\frac{\sigma^{2}}{2}\right) \Delta t, \sigma \sqrt{\Delta t}\right)$

where, $\mu$ is the risk adjusted drift rate of the stochastic demand parameter $\theta$ and $t^{*}$ is the return interval. Consistent with the option literature we calculate continuous-time value returns according to:

$\gamma_{i, \Delta t}=\ln \left(\frac{F_{i}\left(\theta_{t^{*}}\right)}{F_{i}\left(\theta_{0}\right)}\right)$

where, $\gamma_{i, \Delta t}$ is the instantaneous return on the growth option of firm $i$ over the return interval, $\Delta t, F_{i}\left(\theta_{0}\right)$ is the value of the growth option at $t=0$ and $F_{i}\left(\theta_{t^{*}}\right)$ is the value of the growth option at $\mathrm{t}=\mathrm{t}^{*}$.

We note that in the base case we automatically find negative skewness in the return distribution as a property of the log function of continuous-time returns. If the option expires worthless the option return will be minus infinity while this is not compensated by the positive returns of growth options that will be exercised. ${ }^{9}$

\footnotetext{
${ }^{9}$ Our return interval is chosen such that $\mathrm{t}^{*}<\mathrm{t}_{1}$, thereby avoiding the situation that the growth option has a zero payoff and we cannot calculate continuous-time returns because $\ln (0)$ has no solution.
} 
In our base case we use the following parameter setting:

- $\quad \theta_{0}$ : $\quad$ initial level of demand equals 30;

- $\sigma: \quad$ uncertainty in the demand equals $10 \%$;

- $\mu: \quad$ risk adjusted instantaneous drift in demand is $0 ; 10$

- $\quad \alpha: \quad$ risk neutral instantaneous drift in demand is 0 ;

- $\mathrm{r}_{\mathrm{f}}$ : instantaneous risk free rate equals $10 \%$;

- I: investment outlay equals 1000 ;

- $t_{1}$ : first exercise moment of the growth option is after 1 year;

- $t_{2}: \quad$ second exercise moment of the growth option is after 2 years;

- $\Delta \mathrm{t}$ : $\quad$ return interval is 0.75 year.

We construct simulated return distribution of strategic growth option returns for different parameter settings. We first simulate the base case, which is a special case without investment timing differences. Subsequently, we analyze the impact of firstmover advantages on the growth option return distribution in a sequential exercise game.

\section{A. Return Interval Relative to the Life of the Growth Option ( $\Delta t)$}

We simulate the return distribution over different return intervals, $\Delta \mathrm{t}$, where $\Delta \mathrm{t}=\mathrm{t}^{*}-\mathrm{t}_{0}$ and $\mathrm{t}^{*}<\mathrm{t}_{1}$. The other option parameters, including the maturity date of the growth option $t_{1}$, remain constant. The simulation shows that mean returns decrease when the return interval increases. There are two explanations for this relationship. First, the time value of the option $\mathrm{F}_{\mathrm{i}}\left(\theta_{\mathrm{t}^{*}}\right)$ decreases when $\Delta t$ increases and consequently results in lower mean returns. Second, when the return interval approaches the maturity of the growth option, some trajectories of demand are expected to expire worthless because the level of demand is below the investment threshold, yielding large negative returns. The returns generated from these trajectories are not compensated by high demand trajectories.

When we consider the higher moments of the return distribution, we find that the standard deviation in simulated returns increases when the return interval increases. With an increasing cumulative volatility in demand, the distribution of value returns of the growth option widens. Skewness becomes more negative when the return interval 
increases, due the large negative returns of the "out-of-the-money" trajectories. We note that this effect is amplified through continuous-time returns. The kurtosis will be positively influenced due to the same reason.

\section{B. The Level of Demand Relative to the Investment Threshold $\left(\theta_{0} / \theta^{*}\right)$}

The "moneyness" of the strategic growth option, $\theta_{0} / \theta^{*}$ is positively related to the mean strategic growth option returns. Hence, the probability increases that the growth opportunity will be exercised. The standard deviation in option returns declines when $\theta_{0} /$ $\theta^{*}$ increases. For high levels of demand the growth option will start to behave like the underlying asset because the implicit leverage effect inherent to options diminishes. We further find that when demand is near the investment threshold, skewness and kurtosis are highest. Hence the asymmetry in the payoff function is most pronounced for "at-themoney" options (i.e.; the level of demand is near the investment threshold).

A firm's competitive position (e.g., Monopolist, Stackelberg leader or follower), assuming that it does not change over time, has a similar effect on the option return distribution. With a better competitive position the profit value of a firm increases for any given level of demand. The threshold demand level that triggers investment therefore declines and consequently increases the "moneyness" of the growth option.

\section{C. $\quad$ Growth of Demand $(\mu)$}

Similar to the "moneyness" of the growth option, strategic growth option returns are positively related to growth in demand, $\mu$. The expected demand increases over time and makes it is more likely that the option will be exercised, resulting in positive option returns. Higher growth, will increase the likelihood of exercise and therefore lowers the standard deviation (skewness and kurtosis) of option returns.

\section{Demand Uncertainty $(\sigma)$}

Demand uncertainty, $\sigma$, has a mixed effect on the four moments of the option return distribution because it may indirectly affect the growth rate of demand in cases where the uncertainty is priced in the market. We therefore differentiate between specific

10 Our findings remain the same for $\mu=1 / 2 \sigma^{2}$ thereby simulating a mean preserving spread. 
and market uncertainty. Furthermore, we note that demand uncertainty influences the investment threshold, as is shown in Equation (5). We control for this effect in the simulations.

Specific demand uncertainty has a negative effect on mean returns of the strategic opportunity. Similar to the effect of cumulative volatility that we mentioned above, positive returns do not compensate the trajectories with large negative returns. Market uncertainty in demand is priced, and will affect the risk-adjusted drift in $\theta$. In our model we assume that the risk premium associated with systematic demand uncertainty $\theta$ is proportional to its standard deviation, that is

$$
\mu=\frac{\rho_{\theta, M}}{\sigma_{M}}\left(R_{M}-r_{f}\right) \sigma
$$

where, $\rho_{\theta, M}$ is the correlation of changes in demand with the market return, $R_{M}$ is the return on the market portfolio and $\sigma_{M}$ is the standard deviation of the returns of the market portfolio. In our base-case parameter setting the standard deviation of the market portfolio, $\sigma_{M}$, equals $20 \%$, the risk premium, $R_{M}-r_{f}$, equals $5 \%$ and the correlation, $\rho_{\theta, M}$, equals 1 . In contrast to specific uncertainty in demand, market uncertainty in demand may have a positive effect on mean growth options returns. For low levels of market uncertainty in demand, mean option returns are increasing in demand uncertainty because it enhances the risk adjusted growth rate. However, for higher levels of demand uncertainty, the negative effect tends to dominate and mean growth option returns tend to decrease with total demand uncertainty. Skewness and kurtosis decrease when demand uncertainty increases even if we control for "moneyness" of the strategic growth option.

\section{E. Potential Entry and Discontinuities in Payoff}

The payoff function of an incumbent may show discontinuities due to competitive interaction. In a low region of demand $\left(\theta<\theta_{M}\right)$ no firm will invest, for an intermediate level of demand $\left(\theta_{\mathrm{M}}<\theta<\theta_{\mathrm{F}}\right)$ the first mover will act as a monopolist, while at a high level of demand $\left(\theta \geq \theta_{\mathrm{F}}\right)$ a follower will enter, causing a negative jump in the value of the profit flow of the incumbent firm. We analyze the effect of potential entry on the return 
distribution by comparing the proprietary growth option returns of a Monopolist with that of a Stackelberg leader which faces potential entry. Potential entry introduces more (negative) skewness and kurtosis in the return distribution of the strategic option of the incumbent (Stackelberg leader). Thus, the threat of competitive entry introduces more skewness and kurtosis in the growth options return distribution.

\section{F. First-mover Advantages in a Sequential Option Game}

Simulations show that investment timing differences may result in bimodal growth option return distributions for the leader and the follower. Figure 3 illustrates the simulated return distributions for both firms. Panel A presents the return distribution for a firm who acts as a Cournot competitor or Stackelberg leader and Panel B presents the return distribution for a firm that acts as a Cournot competitor or Stackelberg follower (depending on the level of demand).

At high levels of demand $\left(\theta_{\mathrm{t} 1}>\theta_{\mathrm{II}}\right)$, both firms invest and act as a competitor in a symmetrical Cournot equilibrium. These return trajectories are presented by the peaks on the right-hand side in Panel A and Panel B. The high demand trajectories generate high returns for both firms and the returns of the "in-the-money" real options have relatively low skewness and kurtosis.

At low levels of demand $\left(\theta_{\mathrm{t} 1}<\theta_{\mathrm{Ww}}\right)$, both firms defer investment to the next period. These returns generated by the low demand trajectories are presented by the peaks on the left hand side of Panel A and Panel B of Figure 3 respectively. These peaks are characterized by high volatility, skewness and kurtosis.

In the intermediate zone $\left(\theta_{\mathrm{WW}}<\theta_{\mathrm{t} 1}<\theta_{\mathrm{II}}\right)$, the leader preempts the market, introducing the differences in the return distribution in Panel A and B. The leader will invest at $t_{1}$ and acquires a monopoly profit flow. However this competitive position can deteriorate if the follower enters the market in next period. The follower will not invest but acquires an option on a Stackelberg follower payoff in the next period. As a consequence, the follower will experience a significant reduction in growth option value when the leader preempts the market.

To summarize our results, investment-timing differences and preemption can result in bimodal return distributions. The leader has a high probability of generating high 
returns and a low probability of generating low returns, while the follower has a high probability of generating low returns and a low probability of generating high returns.

$<$ Insert Figure 3 about here $>$

\section{CONCLUDING REMARKS}

The stock price behavior of firms with embedded growth options is characterized by high volatility and strategic interactions. Preemption and option characteristics may contribute to the distinguishably different behavior of growth firms.

In this paper we analyze the return dynamics of strategic growth options in a Cournot-Nash framework, where firms may have investment-timing differences. Option parameters (e.g. maturity, profit value relative to the investment, demand uncertainty and drift) and strategic parameters (competitive investment timing and preemption) introduce non-linearity and discontinuities in the payoff and are determinants for the higher moments of the return distribution. Simulations of the different option and strategic parameters provide the following insights:

If the return interval relative to the time to maturity increases, the mean option return decreases, the standard deviation in option returns increases and the return distribution will be more negatively skewed with fatter tails.

Demand relative to the investment trigger, positively influences mean option returns, while it negatively relates to the standard deviation of option returns. Skewness and kurtosis are highest for "at-the-money" growth options. We also observe this effect for growth in demand (drift).

Uncertainty in demand negatively influences mean growth option returns. This relationship is ambiguous if higher uncertainty is caused by market uncertainty in demand because it indirectly affects the growth rate of demand. Skewness and kurtosis decrease when demand uncertainty increases even if we control for the moneyness of the strategic option.

Discontinuities in payoff as a consequence of strategic interaction and preemption, further enhance (negative) skewness and kurtosis. If we allow for investment-timing differences, bimodal return distributions may result where the first mover (follower) has a 
high (low) probability of generating high returns and a low (high) probability of generating low returns.

The combination of options and game theory allows us to proper analyze uncertain strategic effects on returns. The insights in this paper could in principle be empirically tested in financial markets. 


\section{REFERENCES}

Berk, J.B., R.C.Green and V. Naik (2003), "The Valuation and Return Dynamics of New Ventures" Review of Financial Studies, (forthcoming).

Coval, J. and T. Shumway (2001), "Expected Option Returns" Journal of Finance, vol. 56, 3, pp. 983-1009.

Cox, J.C. \& S.A. Ross and M. Rubinstein (1979): "Option Pricing: A Simplified Approach" Journal of Financial Economics, 7, 1979, pp.229-263

Dixit, A., and R. S. Pindyck (1994), Investment Under Uncertainty, Princeton University Press, Princeton N.J.

Galai, D., and R. Masulis (1976) "The Option Pricing Model and the Risk Factor of Stock," Journal of Financial Economics, 3, pp. 53-82.

Grenadier, S. R. (1996), "The Strategic Exercise of Options: Development Cascades and Overbuilding in Real Estate Markets," Journal of Finance, 51, 1653-1679.

Grenadier, S. R. (1999), "Information Revelation Through Option Exercise," Review of Financial Studies, 12, 95-130.

Grenadier, S. R. (2000), "Option Exercise Games: An Application to the Equilibrium Investment Strategies of Firms," Working Paper, Stanford University.

Grenadier, S. R. (2000), Game Choices: The Intersection of Real Options and Game Theory, Risk Books.

Lambrecht, B. and W. Perraudin (2003), "Real Options and Preemption Under Incomplete Information," Journal of Economic Dynamics and Control, 27(4), pp. 619-643.

Kulatilaka, N. and E. Perotti (1998), "Strategic Growth Options," Management Science, 44, pp.1021-1031.

Rubinstein, M. (1984), “A simple Formula for the Expected Rate of Return of an Option over a Finite Holding Period," Journal of Finance, 39, pp. 1503-1509.

Shackleton, M. and R. Wojakowski (2000), "The Expected Return and Exercise Time of Merton-Style Real Options", Working Paper, Lancaster University.

Smit J.T.J. and L. Trigeorgis (1997), "Flexibility and Competitive R\&D Strategies", Working Paper, Erasmus University.

Smit J.T.J. and L. Trigeorgis (2004), Strategic Investment and Option Games, Princeton University Press, Princeton N.J. (forthcoming). 
Trigeorgis, L. (1996), Real Options: Managerial Flexibility and Strategy in Resource Allocation, MIT Press, Boston MA. 


\section{Appendix 1: Value of Infinitive Profit Flow in a Cournot Nash framework}

We assume that $\theta$ follows a Geometric Brownian Motion:

$\frac{d \theta}{\theta}=\alpha d t+\sigma d z$

where $\mathrm{d} \theta$ is the change in $\theta$ for an infinitive small time period $\mathrm{dt}, \alpha$ is the risk neutral drift rate of the stochastic variable $\theta, \sigma$ is the instantaneous standard deviation in the drift rate and $\mathrm{dz}$ is an increment of a Wiener process. The following equation holds for log changes in $\theta$ over a timeframe $\mathrm{T}$ :

$$
\ln \left(\frac{\theta_{T}}{\theta}\right) \sim N\left[\left(\alpha-\frac{\sigma^{2}}{2}\right) T, \sigma \sqrt{T}\right]
$$

Thus at $\mathrm{t}=\mathrm{T}, \theta$ is distributed according to:

$$
\ln \theta_{T} \sim N\left[\ln \theta_{0}+\left(\alpha-\frac{\sigma^{2}}{2}\right) T, \sigma \sqrt{T}\right]
$$

implying that $\theta_{\mathrm{T}}$ has a lognormal distribution with parameters $\mathrm{a}=\ln \theta_{0}+\left(\alpha-\sigma^{2} / 2\right) \mathrm{T}$ and $b=\sigma^{2} \mathrm{~T}$. For the expected value of a variable that is lognormal distributed the following equation holds:

$$
E\left(\theta_{T}^{x}\right)=e^{\left(x a+\frac{x^{2} b^{2}}{2}\right)}=e^{x a} e^{\frac{x^{2} b}{2}}=e^{x\left[\ln \theta_{0}+\left(\alpha-\frac{\sigma^{2}}{2}\right) T\right]} e^{\frac{x^{2} \sigma^{2} T}{2}}
$$

It shows that for $\mathrm{x}=2$ the following holds:

$$
E\left(\theta_{T}^{2}\right)=e^{\left[\left[\ln \theta_{0}+\left(\alpha-\frac{\sigma^{2}}{2}\right) T\right]\right.} e^{\frac{4 \sigma^{2} T}{2}}=\theta_{0}^{2} e^{\left(2 \alpha-\sigma^{2}\right) T} e^{2 \sigma^{2} T}=\theta_{0}^{2} e^{\left(2 \alpha+\sigma^{2}\right) T}
$$


For $\pi_{\mathrm{i}}=\theta^{2} / \mathrm{n}$, the expected profit flow at $\mathrm{t}=\mathrm{T}$ therefore equals:

$$
E\left[\pi_{i}\left(\theta_{T}\right)\right]=\frac{\theta_{0}^{2} e^{\left(2 \alpha+\sigma^{2}\right) T}}{n}
$$

The present value of an infinitive profit flow can be found according to:

$$
V_{0}=\int_{T=0}^{\infty} e^{-r_{f} T}\left[E\left(\pi_{T}\right)\right] d t=\int_{T=0}^{\infty} \frac{\theta_{0}^{2} e^{\left(2 \alpha+\sigma^{2}-r_{f}\right) T}}{n} d t=\frac{\theta_{0}^{2}}{n\left(r_{f}-2 \alpha-\sigma^{2}\right)}
$$

where $2 \alpha+\sigma^{2}>r_{f}$ in order to converge. 


\section{Appendix 2: Value of the Option to Defer in a Cournot-Nash Framework}

Given the investment threshold, $\theta^{*}$, the following integral has to be solved for valuing the option to invest at $\mathrm{t}=\mathrm{T}$ under a given market structure:

$F_{i}(\theta)=e^{-r_{f} T} \int_{\theta^{*}}^{\infty}\left[\frac{\theta_{T}^{2}}{n\left(r_{f}-2 \alpha-\sigma^{2}\right)}-I\right] p\left(\theta_{T}\right) d \theta_{T}$

where, $p\left(\theta_{\mathrm{T}}\right)$ is the risk neutral probability density function of $\theta_{\mathrm{T}}$. Rearranging this integral yields the following result:

$F_{i}(\theta)=\frac{e^{-r_{f} T}}{n\left(r_{f}-2 \alpha-\sigma^{2}\right)} \int_{\theta^{*}}^{\infty} \theta_{T}^{2} p\left(\theta_{T}\right) d \theta_{T}-I e^{-r_{f} T} \int_{\theta^{*}}^{\infty} \theta_{T} p\left(\theta_{T}\right) d \theta_{T}$

We define:

$$
m=\ln [E(\theta)]-\frac{s^{2}}{2} \quad \text { and } \quad q=\frac{\ln \theta-m}{s} \quad \text { and } \quad h(q)=\frac{1}{\sqrt{2 \pi}} e^{-\frac{q^{2}}{2}}
$$

First we solve $\int_{\theta^{*}}^{\infty} \theta^{2} p(\theta) d \theta$ :

$$
\begin{aligned}
& \int_{\frac{\ln \left(\theta^{*}\right)-m}{s}}^{\infty} e^{2 q s+2 m} h(q) d q=\int_{\frac{\ln \left(\theta^{*}\right)-m}{s}}^{\infty} e^{2 q s+2 m} \frac{1}{\sqrt{2 \pi}} e^{\frac{-q^{2}}{2}} d q=\int_{\frac{\ln \left(\theta^{*}\right)-m}{s}}^{\infty} \frac{e^{\frac{-q^{2}}{2}+2 q s+2 m}}{\sqrt{2 \pi}} d q= \\
& \int_{\frac{\ln \left(\theta^{*}\right)-m}{s}}^{\infty} \frac{e^{\frac{-q^{2}+4 q s+4 m}{2}}}{\sqrt{2 \pi}} d q=\int_{\frac{\ln \left(\theta^{*}\right)-m}{s}}^{\infty} \frac{e^{\frac{-(q-2 s)^{2}+4 s^{2}+4 m}{2}}}{\sqrt{2 \pi}} d q=\int_{\frac{\ln \left(\theta^{*}\right)-m}{s}}^{\infty} e^{2 s^{2}+2 m} \frac{1}{\sqrt{2 \pi}} e^{\frac{-(q-2 s)^{2}}{2}} d q= \\
& e^{2 s^{2}+2 m} \int_{\frac{\ln \left(\theta^{*}\right)-m}{s}}^{\infty} h(q-2 s) d q
\end{aligned}
$$


Substituting $q=\frac{\ln \theta-m}{s}$ and $m=\ln [E(\theta)]-\frac{s^{2}}{2}$ yields

$\int_{\theta^{*}}^{\infty} \theta^{2} p(\theta) d \theta=e^{s^{2}} E(\theta)^{2} N\left[\frac{\ln \left(\frac{E(\theta)}{\theta^{*}}\right)+\frac{3}{2} s^{2}}{s}\right]$

Second, we solve $\int_{\theta^{*}}^{\infty} \theta p(\theta) d \theta$ :

$\int_{\frac{\ln \left(\theta^{*}\right)-m}{s}}^{\infty} h(q) d q=N\left[\frac{\ln \left(\frac{E(\theta)}{\theta^{*}}\right)-\frac{1}{2} s^{2}}{s}\right]$

It can be shown that in the risk neutral world the following holds:

$E\left(\theta_{T}\right)=\theta_{0} e^{\alpha T}$

$E\left(\theta_{T}^{2}\right)=\theta_{0}^{2} e^{\left(2 \alpha+\sigma^{2}\right) T}$

$s=\sigma \sqrt{T}$

Substitution Equations A.13-A.17 in A.9 results in:

$F_{i}(\theta)=\frac{e^{-r_{f} T} e^{\sigma^{2} T} e^{2 \alpha T} \theta_{0}^{2}}{n\left(r_{f}-2 \alpha-\sigma^{2}\right)} N\left[\frac{\ln \left(\frac{\theta_{0}}{\theta^{*}}\right)+\left(\alpha+\frac{3}{2} \sigma^{2}\right) T}{\sigma \sqrt{T}}\right]-I e^{-r_{f} T} N\left[\frac{\ln \left(\frac{\theta_{0}}{\theta^{*}}\right)+\left(\alpha-\frac{1}{2} \sigma^{2}\right) T}{\sigma \sqrt{T}}\right]$

Rearranging A.18 results in:

$F_{i}(\theta)=\frac{\theta_{0}^{2} e^{\left(\sigma^{2}+2 \alpha-r_{f}\right) T}}{n\left(r_{f}-2 \alpha-\sigma^{2}\right)} N\left[\frac{\ln \left(\frac{\theta_{0}}{\theta^{*}}\right)+\left(\alpha+\frac{3}{2} \sigma^{2}\right) T}{\sigma \sqrt{T}}\right]-I e^{-r_{f} T} N\left[\frac{\ln \left(\frac{\theta_{0}}{\theta^{*}}\right)+\left(\alpha-\frac{1}{2} \sigma^{2}\right) T}{\sigma \sqrt{T}}\right]$ 
TABLE 1. Profit Flow, Present Value of Profit Flow and Investment Thresholds for a Monopolist, Cournot Competitor, Stackelberg Leader and Stackelberg Follower.

\begin{tabular}{|c|c|c|c|c|}
\hline & Monopolist & Cournot Competition & Stackelberg Leader & Stackelberg Follower \\
\hline Profit flow & $\pi_{\mathrm{M}}(\theta)=\theta^{2} / 4$ & $\pi_{\mathrm{C}}(\theta)=\theta^{2} / 9$ & $\pi_{\mathrm{L}}(\theta)=\theta^{2} / 8$ & $\pi_{\mathrm{F}}\left(\theta_{\mathrm{T}}\right)=\theta^{2} / 16$ \\
\hline PV Profit flow & $\mathrm{V}_{\mathrm{M}}\left(\theta_{\mathrm{T}}\right)=\theta^{2} /\left[4\left(\mathrm{r}_{\mathrm{r}}-2 \alpha-\sigma^{2}\right)\right]$ & $\mathrm{V}_{\mathrm{C}}\left(\theta_{\mathrm{T}}\right)=\theta^{2} /\left[9\left(\mathrm{r}_{\mathrm{r}}-2 \alpha-\sigma^{2}\right)\right]$ & $\mathrm{V}_{\mathrm{L}}\left(\theta_{\mathrm{T}}\right)=\theta^{2} /\left[8\left(\mathrm{r}_{\mathrm{f}}-2 \alpha-\sigma^{2}\right)\right]$ & $\mathrm{V}_{\mathrm{F}}(\theta)=\theta^{2} /\left[16\left(\mathrm{r}_{\mathrm{f}}-2 \alpha-\sigma^{2}\right)\right]$ \\
\hline Critical Thresholds & $\theta_{\mathrm{M}}=2\left[\left(\mathrm{r}_{\mathrm{f}}-2 \alpha-\sigma^{2}\right) \mathrm{I}\right]^{1 / 2}$ & $\theta_{\mathrm{C}}=3\left[\left(\mathrm{r}_{\mathrm{f}}-2 \alpha-\sigma^{2}\right) \mathrm{I}\right]^{1 / 2}$ & $\theta_{\mathrm{L}}=2\left[2\left(\mathrm{r}_{\mathrm{f}}-2 \alpha-\sigma^{2}\right) \mathrm{I}\right]^{1 / 2}$ & $\theta_{\mathrm{F}}=4\left[\left(\mathrm{r}_{\mathrm{f}}-2 \alpha-\sigma^{2}\right) \mathrm{I}\right]^{1 / 2}$ \\
\hline
\end{tabular}

Where, $\pi$ is the profit flow, $\theta$ is the uncertain demand parameter, $r_{\mathrm{f}}$ is the risk free rate, $\alpha$ is the risk neutral growth rate in demand, $\sigma$ is the uncertainty in demand, $\mathrm{V}$ is the value of the profit flow and $\theta_{\mathrm{n}}$ is the investment threshold for market structure $\mathrm{n}$. 
FigurE 1. Extensive Form of the Sequential Investment Game

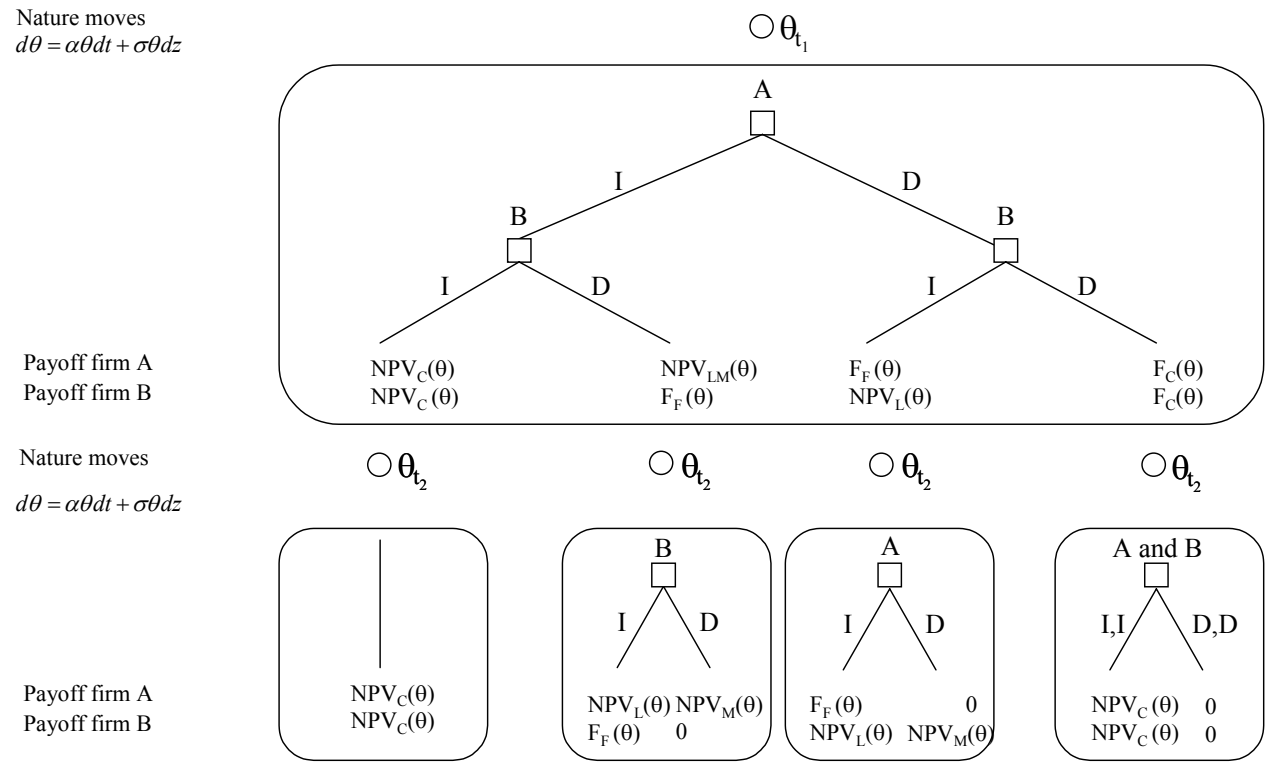

If both firms invest at $t_{1}$ the outcome will be Cournot competition $\left(\mathrm{NPV}_{\mathrm{C}}(\theta)\right)$. If, at $\mathrm{t}_{1}$, one firm invests (L) and the other firm defers (F), the firm that invests will become a Monopolist $\left(\operatorname{NPV}_{\mathrm{LM}}(\theta)\right)$. At $t_{2}$ the firm will either remain a Monopolist $\left(N P V_{M}(\theta)\right)$ if the follower doesn't invests at $t_{2}$ or act as a Stackelberg leader $\left(\operatorname{NPV}_{L}(\theta)\right)$ if the follower invests at $t_{2}$. If a firm defers investment at $t_{1}$ while the other firm invests, he will acquire an option on a Stackelberg follower payoff $\left(\mathrm{F}_{\mathrm{F}}(\theta)\right)$. If both firms defer investment at $t_{1}$ the game will be repeated at $t_{2}$ and both firms will acquire an option on a symmetrical Cournot payoff $\left(\operatorname{NPV}_{C}(\theta)\right)$. If firms do not exercise the growth option on $t_{2}$, the opportunity will expire worthless. 
FIGURE 2. Equilibrium Payoffs as Function of Demand $(\theta)$

Equilibrium Payoff at $t_{1}$ as Function of Demand

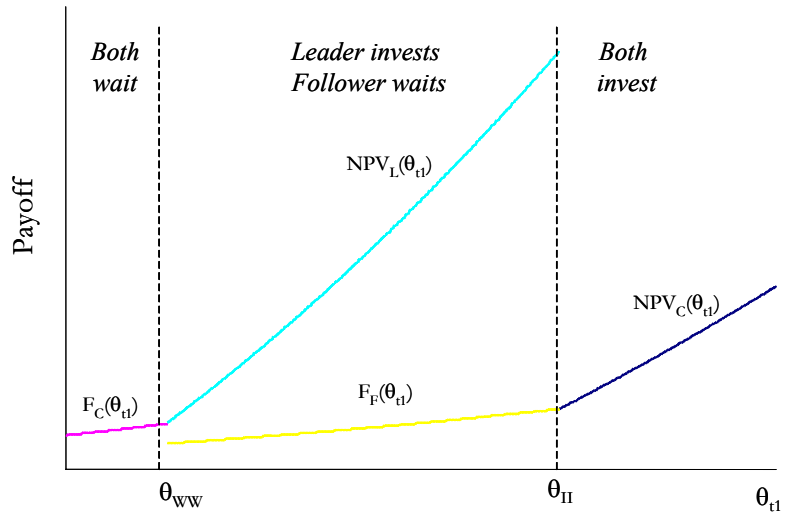

The equilibrium payoff of the growth option at $t_{1}$ is a discontinous function of demand. For low levels of demand $\left(\theta_{\mathrm{t} 1}<\theta_{\mathrm{Ww}}\right)$ both firms will defer investment. For intermediate levels of demand $\left(\theta_{\mathrm{WW}}<\theta_{\mathrm{tl}}<\theta_{\mathrm{II}}\right.$ ) the firm that moves first will invest while the follower will defer investment to the next period. For high levels of demand $\left(\theta_{\mathrm{tl}}>\theta_{\mathrm{II}}\right)$ both firms will invest. The game may results in discontinuities and jumps in the equilibrium payoff of the growth option because of investment-timing differences. 
FIGURE 3. Return Distribution of Leader (left) and Follower (right) in a Sequential Investment Game

A. Cournot Competitor/Stackelberg Leader

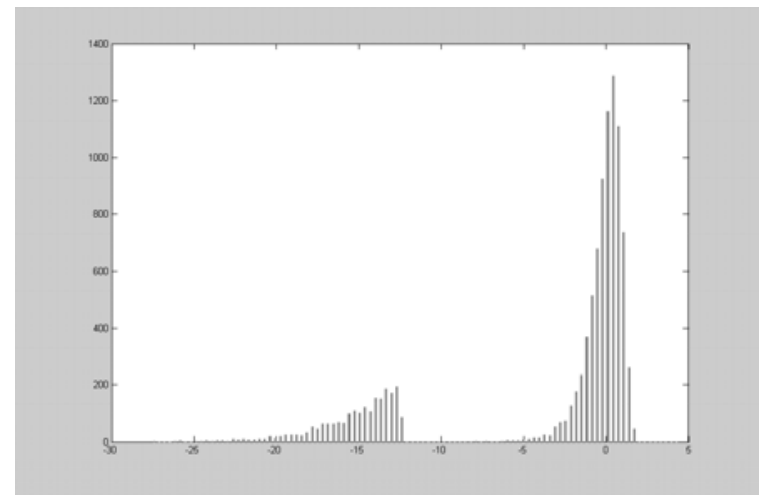

B. Cournot Competitor/Stackelberg Follower

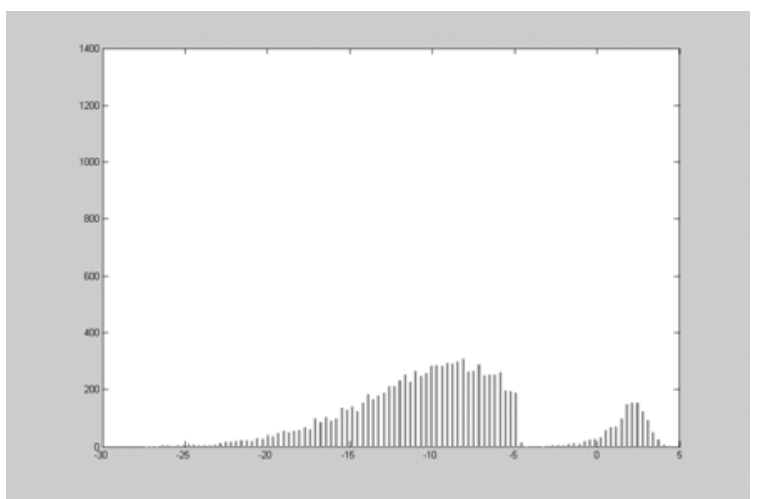

The return distribution in a two-staged investment game where the firm has a first mover advantage and $\zeta_{\mathrm{i}}=1$ (left) or is a follower and $\zeta_{\mathrm{i}}=0$ (right). Investment-timing differences may result in bimodial growth option return distributions where the firm having a first mover advantage has a high (low) probability of generating high (low) returns while the follower has a high (low) probability of generating low (high) returns. $\left(\sigma=10 \%, \mu=0, \alpha=0, I=1000, \mathrm{r}_{\mathrm{f}}=10 \%, \mathrm{t}_{1}=1, \mathrm{t}_{2}=2, \mathrm{t}^{*}=1, \theta_{0}=30, \mathrm{n}=10.000\right)$ 